\title{
Antibiose e não preferência para oviposição de Bemisia tabaci (Genn.) biótipo B (Hemiptera: Aleyrodidae) em genótipos de feijoeiro comum
}

\author{
Antibiosis and non preference for the oviposition of Bemisia tabaci (Genn.) \\ biotype B (Hemiptera: Aleyrodidae) in common bean genotypes
}

\author{
Marília Lara Peixoto $^{1 *}$, Arlindo Leal Boiça Júnior ${ }^{1}$

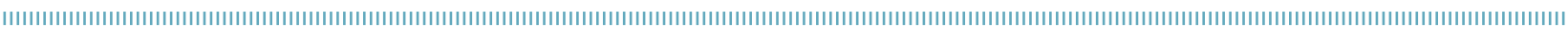

RESUMO: O feijoeiro comum, Phaseolus vulgaris L., constitui importante fonte de proteína e renda para muitos países, entre eles, o Brasil. Diferentes fatores contribuem para a reduçáo da produção, como os insetos pragas, destacando-se Bemisia tabaci (Genn.) biótipo B. O presente trabalho teve por objetivo identificar genótipos de feijoeiro comum resistentes à $B$. tabaci biótipo $\mathrm{B}$ e os tipos de resistência envolvidos. Para isso, foram realizados dois experimentos desenvolvidos em laboratório e em casa-de-vegetaçáo, avaliando-se 11 genótipos de feijoeiro comum. Para o teste com chance de escolha, o delineamento utilizado foi o de blocos casualizados, e para os testes sem chance de escolha e antibiose, a escolha foi pelo inteiramente casualizado, totalizando seis repetições para cada teste. As variáveis avaliadas foram: período de incubaçáo dos ovos; período ninfal; período de ovo a adulto; viabilidade de ovo a adulto e longevidade de adultos. O genótipo IAC-Harmonia prolongou os períodos ninfal e de ovo a adulto de B. tabaci biótipo B. Os genótipos testados foram igualmente ovipositados pela mosca-branca, em testes com e sem chance de escolha.

PALAVRAS-CHAVE: mosca-branca; tipos de resistência de plantas; Phaseolus vulgaris.
ABSTRACT: The common bean Phaseolus vulgaris L. constitutes an important source of protein and income for many countries, including Brazil. Different factors contribute with the reduction in production, including pest insects, especially Bemisia tabaci (Genn.) biotype B. This study aimed to identify common bean genotypes resistant to $B$. tabaci biotype $B$ and the types of resistance involved. Therefore, two experiments were developed in a greenhouse and laboratory, evaluating 11 common bean genotypes. To test the free-choice experimental design, the randomized block design was adopted, and the completely randomized one was selected for the no-choice tests and antibiosis, with six replications for each test. The following variables were evaluated: incubation period of eggs; nymphal; egg to adult; viability of egg to adult and adult longevity. The IAC-Harmony prolonged the nymphal and egg to adult periods of B. tabaci biotype B. The genotypes were also tested by the whitefly oviposition in free and no choice tests.

KEYWORDS: silverleaf whitefly; type of plant resistance; Phaseolus vulgaris. 


\section{INTRODUÇÃO}

Phaseolus vulgaris L. é a espécie mais cultivada de feijoeiro comum dentro da família botânica Fabaceae. Constitui uma das mais importantes fontes de proteína na dieta alimentar de grande parcela da população mundial (ANTUNEs et al., 1995).

A produção brasileira do grão na safra de 2011/2012 foi de 2.890,00 toneladas, em uma área colhida de 3.256,00 ha; a produção na regiáo Sudeste do país foi de 991 toneladas. O consumo per capita é de $18,29 \mathrm{~kg} /$ habitante/ano (Agrianual, 2013).

Os insetos pragas contribuem para a diminuição da produçấo desta leguminosa, e a mosca-branca, Bemisia tabaci (Genn.) biótipo $\mathrm{B}$, é uma das principais pragas devido à injeção de toxina e da transmissão de vírus como o causador do mosaico dourado do feijoeiro (Yокоунма, 1996; Brown, 2000). As perdas econômicas ocasionadas por esse vírus podem variar de 30 a 100\%, sendo influenciadas pela presença de hospedeiros alternativos e pelas condiçóes ambientais. Os danos também podem variar conforme a cultivar utilizada, o estádio de desenvolvimento a planta e a porcentagem de infecção pelo vírus (FARIA et al., 1996).

O controle de $B$. tabaci é realizado principalmente por meio da aplicação de produtos químicos, sendo que a utilização intensiva de inseticidas pode levar ao desenvolvimento de insetos resistentes (Prabhaker et al., 1985; Dennehy et al., 2008) além de outros problemas gerados ao agroecossistema. A redução nas aplicações de inseticidas e a associação com outros métodos de controle da praga são medidas importantes para evitar esses problemas (Denholm et al., 1998).

O uso de variedades resistentes é considerado o método ideal em um programa de manejo integrado de pragas (MIP), com grande potencial no controle da mosca-branca (MCauslane, 1996). Características morfológicas ou fisiológicas da planta, como o número e o tipo de tricomas, ou a concentração de compostos químicos, podem conferir algum tipo de resistência ao genótipo (Meagher Junior et al., 1997).

Estudos de variedades resistentes à $B$. tabaci biótipo $\mathrm{B}$ vem sendo realizados em feijoeiros, como os que foram desenvolvidos por Oriani; LARA (2000), que constataram que os materiais selvagens Arc 3 s e Arc 5s apresentaram resistência do tipo não preferência para oviposição. Em outro trabalho, OrIANI et al. (2005) verificaram que esses mesmos materiais selvagens de feijoeiro apresentaram não preferência para alimentação e/ou antibiose.

De acordo com Boiça Júnior; Vendramim (1986), o cultivar de feijoeiro Bolinha influenciou negativamente o ciclo de vida de $B$. tabaci, sugerindo resistência do tipo antibiose.

BIANCHINI (1994) lançou as linhagens IAPAR 57 e IAPAR 72 (grão carioca), assim como a linhagem IAPAR 65 (grão preto) como resistentes ao vírus do mosaico dourado, sendo todas recomendadas para o plantio em regiôes do sul do Brasil.

LEMos et al. (2003) observaram que os genótipos IAPAR 57 , IAPAR 65, IAPAR 72, Ônix, Aporé e 606 (5)(214-17) destacaram-se como os mais tolerantes ao vírus do mosaico dourado e ao ataque da mosca-branca.

Em estudo realizado por Torres et al. (2012), os genótipos ARC-3, IAC-Alvorada e Canário 101 podem ter apresentado o tipo de resistência por não preferência para alimentação e/ou antibiose, já que o primeiro acarretou $100 \%$ de mortalidade dos imaturos, náo diferindo das médias obtidas para os dois últimos, que propiciaram a emergência de apenas 3,3\% de adultos.

Diante desses relatos, o uso de cultivares resistentes demonstra ser promissor em um programa de manejo integrado da mosca-branca na cultura do feijoeiro. $\mathrm{O}$ trabalho teve por objetivo identificar genótipos de feijoeiro comum resistentes à $B$. tabaci biótipo $\mathrm{B}$ e os tipos de resistência envolvidos.

\section{MATERIAL E MÉTODOS}

Os experimentos de antibiose e de não preferência para oviposição foram conduzidos em casa-de-vegetação em condiçóes naturais, e a contagem do número de ovos nas folhas das plantas de feijão foi avaliada em laboratório através de estereomicroscópico, em Jaboticabal (SP).

Foram utilizados os seguintes genótipos de feijoeiro: IAC-Harmonia, IAC-Carioca Tybatã, Pérola, IAC-Una, IAC-Diplomata, IPR-Siriri, IAPAR 81, IAC-Alvorada, BRS Pontal, IAC-Formoso, BRS Requinte.

As sementes de feijão foram semeadas em vasos de polietileno com capacidade para cinco litros, sendo quatro sementes por vaso. As plantas foram desbastadas dez dias após a emergência, deixando-se uma planta por vaso.

Os espécimes de B. tabaci biótipo B utilizados no experimento foram adquiridos da criaçáo de manutenção em casa-de-vegetação do setor de Entomologia, no Departamento de Fitossanidade da FCAV/UNESP, mantidas em plantas de couve cultivar Manteiga Georgia (Brassica oleracea L. var. acephala). A populaçấo inicial foi proveniente de criação mantida no Instituto Agronômico de Campinas (IAC). Fontes et al. (2010) confirmaram a identidade dos insetos dessa criação por meio de RAPD.

\section{Teste de antibiose em B. tabaci biótipo B}

Para esse estudo, os 11 genótipos (Tabela 1) foram avaliados em um experimento em delineamento inteiramente casualizado, com seis repetiçóes.

Quando as plantas se encontravam no estádio vegetativo V3 (primeira folha trifoliada), foram coletados adultos não sexados de mosca-branca da criação de manutenção através de um sugador manual de borracha, acoplado a um tubo de ensaio de vidro (CAMpos et al., 2009). 
Para cada planta, foi utilizada uma folha na qual se fixou uma gaiola de plástico, contendo adultos de mosca-branca para obtenção de ovos. A gaiola foi confeccionada com copos plásticos com capacidade de $40 \mathrm{~mL}$, cujo fundo foi tampado com tecido voil. Uma tampa feita de papeláo e espuma foi colocada na extremidade menor para não causar danos à folha. $\mathrm{O}$ copo foi acoplado a uma haste de madeira para fixação ao solo. A gaiola foi presa à folha por um grampo de metal (CAMPos et al., 2009). Para a obtenção dos ovos, foram colocados 60 adultos de mosca-branca por gaiola/planta.

Após 24 horas, as gaiolas com os adultos foram retiradas e as folhas contendo os ovos foram marcadas para avaliação diária em estereomicroscópico.

Após a eclosão, 15 ninfas de primeiro ínstar foram separadas para avaliação do ciclo biológico. Os parâmetros analisados foram: período de incubação dos ovos; período ninfal; período de duração de ovo a adulto; viabilidade de ovo a adulto e longevidade.

Por ocasiāo do quarto ínstar ninfal, ou seja, na fase de "pupa", foram colocados saquinhos de voil na folha, nos quais foram coletados os adultos emergidos. Estes foram coletados com sugador manual e individualizados em tubos de ensaio. Depois, foram armazenados em laboratório a $26 \pm 2{ }^{\circ} \mathrm{C}$, umidade relativa de $70 \pm 5 \%$ e fotofase de 12 horas, sem alimentação, para a avaliação da longevidade.

\section{Testes de não preferência para oviposição de B. tabaci biótipo B, com e sem chance de escolha}

Quando as plantas se encontravam em estádio vegetativo V4 (terceira folha trifoliada), foram realizados os testes de não preferência para oviposição, com e sem chance de escolha. Os genótipos selecionados no teste de antibiose foram utilizados nesse experimento, totalizando oito: IAC-Harmonia, IAC-Carioca Tybatã, Pérola, IAC-Una, IAC-Diplomata, IPR-Siriri, IAC-Alvorada, BRS Pontal.

\section{Teste com chance de escolha}

Utilizou-se o delineamento em blocos ao acaso, com seis blocos e oito tratamentos (genótipos). Cada bloco foi formado por uma gaiola de metal (1,5 m de comprimento $\mathrm{x} 1,5 \mathrm{~m}$ de largura x 1,8 m de altura), revestida por tela antiafídeo com as plantas dos oito genótipos dispostas em círculo e ao acaso, equidistantes do centro. Aproximadamente 100 adultos de mosca-branca foram liberados no centro da gaiola por planta, totalizando aproximadamente 800 adultos por gaiola.

Após 48 horas, todas as folhas de cada planta foram retiradas, acondicionadas em sacos de papel devidamente identificados e armazenadas em geladeira. A contagem dos ovos foi realizada por meio de estereoscópico, com a observação da face abaxial das folhas. Após essa contagem, foi feita a medição da área foliar, em medidor modelo LI-COR $3100^{\circledR}$, para a obtenção do número de ovos por $\mathrm{cm}^{2}$ de folha.

\section{Teste sem chance de escolha}

Para a realização deste teste, utilizou-se o delineamento inteiramente casualizado, com oito tratamentos (genótipos) e seis repetiçôes. Cada genótipo foi individualizado por gaiola cilíndrica de metal ( $60 \mathrm{~cm}$ de altura $\mathrm{x} 40 \mathrm{~cm}$ de diâmetro), revestida com tecido voil.

Tabela 1. Período médio de incubação dos ovos, período ninfal, duração de ovo a adulto, longevidade (dias) e viabilidade de ovo a adulto (\%) de Bemisia tabaci biótipo B obtidos em genótipos de feijoeiro comum em casa-de-vegetação, Jaboticabal (SP), 2012.

\begin{tabular}{lccccc} 
Genótipos & $\begin{array}{c}\text { Período incubação } \\
\text { (dias) }\end{array}$ & $\begin{array}{c}\text { Período ninfal } \\
\text { (dias) }\end{array}$ & $\begin{array}{c}\text { Duração de } \\
\text { ovo-adulto (dias) }\end{array}$ & $\begin{array}{c}\text { Viabilidade de } \\
\text { ovo-adulto (\%) }\end{array}$ & $\begin{array}{c}\text { Longevidade } \\
\text { adultos (dias) }\end{array}$ \\
\hline IAC-Harmonia & $8,00 \mathrm{~b}$ & $21,00 \mathrm{a}$ & $29,00 \mathrm{a}$ & $91,11 \mathrm{a}$ & $1,14 \mathrm{a}$ \\
\hline IAC-Carioca Tybatã & $8,59 \mathrm{a}$ & $19,26 \mathrm{ab}$ & $27,85 \mathrm{ab}$ & $91,11 \mathrm{a}$ & $1,41 \mathrm{a}$ \\
\hline BRS Pontal & $8,03 \mathrm{~b}$ & $19,13 \mathrm{ab}$ & $27,27 \mathrm{abc}$ & $100,00 \mathrm{a}$ & $1,25 \mathrm{a}$ \\
\hline IAC-Diplomata & $8,03 \mathrm{~b}$ & $19,14 \mathrm{ab}$ & $27,17 \mathrm{abc}$ & $100,00 \mathrm{a}$ & $1,46 \mathrm{a}$ \\
\hline IPR-Siriri & $8,00 \mathrm{~b}$ & $18,79 \mathrm{ab}$ & $26,79 \mathrm{abc}$ & $100,00 \mathrm{a}$ & $1,25 \mathrm{a}$ \\
\hline IAC-Una & $8,00 \mathrm{~b}$ & $18,55 \mathrm{~b}$ & $26,55 \mathrm{bc}$ & $100,00 \mathrm{a}$ & $1,26 \mathrm{a}$ \\
\hline IAC-Alvorada & $8,00 \mathrm{~b}$ & $18,49 \mathrm{~b}$ & $26,49 \mathrm{bc}$ & $100,00 \mathrm{a}$ & $1,33 \mathrm{a}$ \\
\hline IAC-Formoso & $8,19 \mathrm{~b}$ & $18,05 \mathrm{~b}$ & $26,25 \mathrm{bc}$ & $98,89 \mathrm{a}$ & $1,33 \mathrm{a}$ \\
\hline BRS Requinte & $8,15 \mathrm{~b}$ & $18,07 \mathrm{~b}$ & $26,21 \mathrm{bc}$ & $100,00 \mathrm{a}$ & $1,26 \mathrm{a}$ \\
\hline IAPAR 81 & $8,00 \mathrm{~b}$ & $17,32 \mathrm{~b}$ & $25,32 \mathrm{c}$ & $100,00 \mathrm{a}$ & $1,30 \mathrm{a}$ \\
\hline Pérola & $8,03 \mathrm{~b}$ & $16,89 \mathrm{~b}$ & $24,93 \mathrm{c}$ & $100,00 \mathrm{a}$ & $1,28 \mathrm{a}$ \\
\hline F (tratamento) & $5,45^{* *}$ & $4,67^{* *}$ & $4,84^{* *}$ & $2,07^{*}$ & $1,00^{\mathrm{NS}}$ \\
\hline CV (\%) & 2,29 & 6,65 & 4,69 & 6,17 & 16,03 \\
\hline
\end{tabular}

Médias seguidas de mesma letra na coluna não diferem estatisticamente entre si pelo teste de Tukey, a $5 \%$ de probabilidade. 
Cada planta foi infestada com cerca de 100 adultos de mosca-branca, e o tubo $(2,5 \times 8,5 \mathrm{~cm})$ com os insetos foi colocado na base das plantas dos genótipos de feijoeiro.

Após 48 horas, todas as folhas foram retiradas e acondicionadas em sacos de papel devidamente identificados e armazenados em geladeira para posterior manuseio. O número de ovos e a área foliar foram determinados utilizando a mesma metodologia empregada no teste com chance de escolha.

\section{RESULTADOS E DISCUSSÃO}

\section{Teste de antibiose em B. tabaci biótipo B}

O período médio de incubaçáo dos ovos de $B$. tabaci variou de 8,00 dias, nos genótipos IPR-Siriri, IAPAR 81, IAC-Alvorada, IAC-Una e IAC-Harmonia, a 8,59 dias, no genótipo IAC-Carioca Tybatã (Tabela 1).

Oriani et al. (2008) observaram um período semelhante em cultivares de feijoeiro comum, variando entre 7,7 (Porrillo 70) e 8,0 dias (G11056) em ensaios conduzidos em laboratório sob temperatura de $23 \pm 2^{\circ} \mathrm{C}$, umidade relativa de $70 \pm 10 \%$. Estudos realizados por Oriani; Lara (2000) revelaram período de incubação dos ovos variando de 7,5 (ARC 1, ARC 5s) a 8,2 dias (IAPAR MD 808), também em feijoeiro comum em condições naturais em casa-de-vegetação.

Para o período ninfal, constatou-se uma variação entre 16,89 e 21,00 dias, sendo o genótipo Pérola o que induziu à menor média, e o genótipo IAC-Harmonia o que ocasionou o maior período de desenvolvimento das ninfas (Tabela 1). Dados semelhantes foram obtidos por ORIANI et al. (2008) na cultura do feijão comum, com duração de 13,3 dias (Porrillo 70) a 18,8 dias (Arc 3s) em ensaios conduzidos em laboratório sob temperatura de $23 \pm 2^{\circ} \mathrm{C}$, e umidade relativa de $70 \pm 10 \%$.

Para o período de ovo a adulto, os genótipos Pérola e IAPAR 81 foram os que proporcionaram menor duração (24,93 e 25,32 dias, respectivamente), diferindo dos genótipos IAC-Harmonia (29,0 dias) e IAC-Carioca Tybatã (27,85 dias) (Tabela 1).

Em relação à viabilidade de ovo a adulto, não houve diferença entre os genótipos. Foram verificadas, em termos absolutos, as menores médias nos genótipos IAC-Carioca Tybatã e IAC-Harmonia (91,11\%) (Tabela 1).

Quanto à longevidade de adultos também não houve diferença entre os genótipos de feijoeiro, sendo, em termos absolutos, a menor duração de 1,14 dias em IAC-Harmonia e a maior, de 1,46 dias em IAC-Diplomata (Tabela 1).

Os dados biológicos de B. tabaci biótipo B obtidos para o genótipo IAC-Harmonia sugerem um possível mecanismo de resistência pela não preferência para alimentação e/ou antibiose, já que afetou negativamente o desenvolvimento do inseto. Pelos dados, verifica-se um prolongamento de 4,07 dias no período de ovo a adulto do inseto no genótipo IAC-Harmonia em relação ao Pérola, o qual se destacou como o mais adequado ao desenvolvimento desta mosca-branca. De acordo com LARA (1991), quando os insetos necessitam de um tempo maior para completar o estágio imaturo, sugere-se o tipo de resistência de não preferência para alimentação e/ou antibiose.

\section{Teste de não preferência para oviposição de B. tabaci biótipo B}

Para o teste com chance de escolha, considerando o número de ovos por $\mathrm{cm}^{2}$, os genótipos náo diferiram entre si (Tabela 2), variando de 0,79 (IPR-Siriri) a 2,63 ovos por $\mathrm{cm}^{2}$ (BRS Pontal).

Para o teste sem chance de escolha, as médias do número de ovos por $\mathrm{cm}^{2}$ também não diferiram entre os genótipos (Tabela 2), sendo o menor número de ovos por $\mathrm{cm}^{2} \mathrm{de} 0,46$, para IAC-Harmonia, e o maior, de 1,36 ovos por $\mathrm{cm}^{2}$, em IAC-Diplomata.

Jesus et al. (2009), analisando o número de ovos de B. tabaci biótipo B entre os genótipos IAC-Harmonia, IAC-Centauro, Pérola e Carioca, em cinco amostragens (aos 14, 21, 28, 35 e 42 dias após a emergência das plantas), verificaram que não houve diferença entre os genótipos em nenhuma das avaliaçóes.

Jesus (2007) verificou que o número médio de ovos de $B$. tabaci obtidos em seis amostragens em campo efetuadas 25, 32, 39, 46, 53 e 60 dias depois da emergência das plantas de 19 genótipos de feijoeiro não

Tabela 2. Número médio de ovos de Bemisia tabaci biótipo $B$ por $\mathrm{cm}^{2}$ de folíolo, em genótipos de Phaseolus vulgaris, em testes com e sem chance de escolha. Jaboticabal (SP), 2012.

\begin{tabular}{lcc} 
& \multicolumn{2}{c}{ Número de ovos/cm ${ }^{2}$} \\
\cline { 2 - 3 } Genótipos & $\begin{array}{c}\text { Teste com } \\
\text { chance }\end{array}$ & $\begin{array}{c}\text { Teste sem } \\
\text { chance }\end{array}$ \\
\hline IPR-Siriri & $0,79 \mathrm{a}$ & $0,94 \mathrm{a}$ \\
\hline IAC-Alvorada & $0,97 \mathrm{a}$ & $0,61 \mathrm{a}$ \\
\hline IAC-Diplomata & $1,06 \mathrm{a}$ & $1,36 \mathrm{a}$ \\
\hline IAC-Una & $1,39 \mathrm{a}$ & $0,96 \mathrm{a}$ \\
\hline Pérola & $1,62 \mathrm{a}$ & $0,93 \mathrm{a}$ \\
\hline IAC-Carioca Tybatã & $2,10 \mathrm{a}$ & $0,70 \mathrm{a}$ \\
\hline IAC-Harmonia & $2,49 \mathrm{a}$ & $0,46 \mathrm{a}$ \\
\hline BRS Pontal & $2,63 \mathrm{a}$ & $1,00 \mathrm{a}$ \\
\hline F & $1,18^{\mathrm{Ns}}$ & $0,95^{\mathrm{Ns}}$ \\
\hline CV (\%) & 31,95 & 22,84 \\
\hline
\end{tabular}

Médias seguidas de mesma letra na coluna não diferem estatisticamente entre si pelo teste de Tukey, a 5\% de probabilidade. Para análise, os dados foram transformados em $\log (x+5)$. 
diferiram entre si em avaliaçóes nas três safras de cultivo, entre eles IAC-Carioca Tybatã, Pérola, IAC- Alvorada, IAC-Diplomata, BRS Pontal, IAC-Una, genótipos que também foram testados nessa pesquisa. o tipo de resistência de não preferência para alimentação e/ou antibiose.

Os genótipos testados foram igualmente ovipositados por essa mosca-branca, em testes com e sem chance de escolha.

\section{CONCLUSÕES}

O genótipo IAC-Harmonia prolongou os períodos ninfal e de ovo a adulto de B. tabaci biótipo B, caracterizando

\section{AGRADECIMENTO}

À Coordenação de Aperfeiçoamento de Pessoal de Nível Superior (CAPES) pela concessão da bolsa à primeira autora.

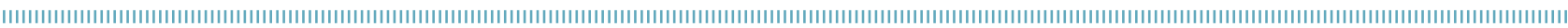

\section{REFERÊNCIAS}

Anuário de Agricultura Brasileira. AGRIANUAL. São Paulo: FNP Consultoria e Agroinformáticos, 2013. p.289-294.

ANTUNES, P.L.; BILHALVA, A.B.; ELIAS, M.C.S.; GERMANO, J.D. Valor nutricional de feijão (Phaseolus vulgaris, L.), cultivares Rico 23, Carioca, Piratã-1 e Rosinha-G2. Revista Brasileira de Agrociência, Pelotas, v.1, n.1, p.12-18, 1995.

BIANCHINI, A. Novas linhagens de feijoeiro resistentes ao vírus do mosaico dourado e cultivares recomendadas para o controle da virose. Fitopatologia Brasileira, v.19, p.329, 1994.

BOIÇA JÚNIOR, A.L.; VENDRAMIM, J.D. Desenvolvimento de Bemisia tabaci em genótipos de feijão. Anais da sociedade entomológica do Brasil, Porto Alegre, v. 15, n.2, p.231-238, 1986.

BROWN, J.K. Molecular markers for the identification and global tracking of whitefly vector-begomovirus complexes. Virus Research, v.71, p.233-260, 2000.

CAMPOS, Z.R.; BOIÇA JUNIOR, A.L.; LOURENÇÃO, A.L.; CAMPOS, A.R. Parâmetros biológicos de Bemisia tabaci (Genn.) biótipo B (Hemiptera:Aleyrodidae) em genótipos de algodoeiro. Bragantia, Campinas, v.68, n.4, p.1003-1007, 2009.

DENNEHY, T.J.; DEGAIN, B.A.; HARPOLD, V.S. Biotype designations and insecticide susceptibility of southwestern Bemisia tabaci. Vegetable Report, v.152, p.23-50, 2008.

DENHOLM, I.; CAHILL, M.; DENNEHY, T.J.; HOROWITZ, A.R. Challenges with managing insecticide resistance in agricultural pests exemplified by the whitefly Bemisia tabaci. Philosophical Transactions Royal Society (Lond. B), v.353, n.1376, p.1757-1767, 1998.

FARIA, J.C.; ANJOS, J.R.N.; COSTA, A.F.; SPERÂNDIO, C.A.; COSTA, C.L. Doenças causadas por vírus e seu controle. In: ARAÚJO, R.D.; RAVA, C.A.; STONE, L.F.; ZIMMERMANN, M.J.O. (eds.). Cultura do feijoeiro comum no Brasil. Piracicaba: POTAFOS, 1996. p.731-769.
FONTES, F.H.M.; COLOMBO, C.A.; LOURENÇÃO, A.L. Caracterização molecular e divergência genética de Bemisia tabaci (Genn.) (Hemiptera: Aleyrodidae) em diferentes culturas e locais de cultivo. Neotropical Entomology, v.39, p.221-226, 2010.

JESUS, F.G. Resistência de genótipos de feijoeiro ao ataque de Bemisia tabaci (Genn.) biótipo B (Hemiptera:Aleyrodidae) e Caliothrips phaseoli (Hood.) (Thysanoptera:Thripidae). 2007. $83 \mathrm{f}$. Tese (Doutorado) - Curso de Pós-graduação em Entomologia Agrícola, Faculdade de Ciências Agrárias e Veterinárias, Universidade Estadual Paulista Júlio de Mesquita Filho, Jaboticabal, 2007.

JESUS, F.G.; BOIÇA JUNIOR, A.L.; JANINI, J.C.; SILVA, A.G.; CARBONEL, S.A.M.; CHIORATO, A.F. Interação de variedades, óleo de nim e inseticidas no controle de Bemisia tabaci (Gennadius) biótipo B e Caliothrips phaseoli (Hood) (Thysanoptera: Thripidae). Boletín de Sanidad Vegetal Plagas, Madrid, v.35, n.3, p.491-500, 2009.

LARA, F.M. (2 Ed.). Princípios de resistência de plantas a insetos. São Paulo: Ícone, 1991. 336p.

LEMOS, L.B.; FORNASIERI FILHO, D.; SILVA, T.R.B.; SORATTO, R.P. Suscetibilidade de genótipos de feijão ao vírus-do-mosaicodourado. Pesquisa Agropecuária Brasileira, Brasília, v.38, n.5, p.575-581, 2003.

MCAUSLANE, H.J. Influence of leaf pubescence on ovipositional preference of Bemisia argentifolii (Homoptera: Aleyrodidae) on soybean. Environmental Entomology, College Park, v.25, n.4, p.834-841, 1996.

MEAGHER JUNIOR, R.L.; SMITH, C.W.; SMITH, W.J. Preference of Gossypium genotypes to Bemisia argentifolii (Homoptera: Aleyrodidae). Journal of Economic Entomology, College Park, v.90, n.4, p.1046-1052, 1997. 
ORIANI, M.A.G.; LARA, F.M. Antibiosis effects of wild bean lines containing arcelin on Bemisia tabaci (Genn.) biotype B (Homoptera:Aleyrodidae). Anais da Sociedade Entomológica do Brasil, Londrina, v.29, n.3, p.573-582, 2000.

ORIANI, M.A.G.; VENDRAMIM, J.D.; BRUNHEROTTO, R. Influência dos tricomas na preferência para oviposição de Bemisia tabaci (Genn.) biótipo B (Hemiptera:Aleyrodidae) em genótipos de feijoeiro. Neotropical Entomology, Londrina, v.34, n.1, p.97-103, 2005.

ORIANI, M.A.G.; VENDRAMIM, J.D.; BRUNHEROTTO, R. Aspectos biológicos de Bemisia tabaci (Genn.) biótipo B
(Hemiptera:Aleyrodidae) em seis genótipos de feijoeiro. Neotropical Entomology, Londrina, v.37, n.2, p.191-195, 2008.

PRABHAKER, N.D.; COUDRIET, D.L.; MEYERDIRK, D.E. Insecticide resistance in the sweetpotato Bemisia tabaci(Homoptera:Aleyrodidae). Journal of Economic Entomology, v.78, p.748-752, 1985.

TORRES, L.C.; SOUZA, B.; LOURENÇÃO, A.L.; COSTA, M.B.; AMARAL, B.B.; CARBONELL, S.A.M.; CHIORATO, A.F.; TANQUE, R.L. Resistência de genótipos de feijoeiro a Bemisia tabaci biótipo B. Bragantia, Campinas, v.71, n.3, p.346-354, 2012.

YOKOYAMA, M. Principais pragas e seu controle. In: ARAÚJO, R.D. (ed.). Cultura do feijoeiro comum no Brasil. Piracicaba: Potafos, 1996. p.771-783. 